\title{
Sobre las autoras y los autores
}

Chiara Bolognese es Doctora en Literatura Hispanoamericana por la Universidad Autónoma de Madrid (2007) y Professore Associato en la Università degli Studi di Roma La Sapienza. Ha participado en varios proyectos de investigación, como «Inventario de mitos prehispánicos en la literatura latinoamericana (desde 1980 hasta el presente)» (Plan Nacional, España) o «Fondo Alicia Kozameh» (Ministère de la Recherche de Francia). Es autora de Pistas de un naufragio. Cartografía de Roberto Bolaño (Alción Editora, 2010). Ha coeditado Este que ves, engaño colorido. Literaturas, culturas y sujetos alternos en América Latina (Icaria, 2012).

Vicente Cervera Salinas es Catedrático de Literatura Hispanoamericana en la Universidad de Murcia, España. Sobre la obra de Borges ha publicado: La poesía de Jorge Luis Borges: historia de una eternidad (Editum, 1992) y Borges en la Ciudad de los Inmortales (Renacimiento, 2015). Es Premio de Ensayo Antrhopos con La poesía y la idea. Fragmentos de una vieja querella (2007) y ha editado a autores como Pedro Henríquez Ureña (Verbum, 2007) o Virgilio Piñera (Cátedra, 2008). También ha publicado La poesía del logos (Editum, 1992), La palabra en el espejo. Estudios de Literatura hispanoamericana comparada (Editum, 1996) y El síndrome de Beatriz en la literatura hispanoamericana (Iberoamericana Vervuet, 2006). Como poeta, destaca su poemario El alma oblicua (2003), traducido al francés, italiano y portugués. Fue presidente de la Asociación de Estudios Literarios Hispanoamericanos y es codirector de la revista de investigación y crítica estética Cartaphilus.

Mariana Di Ció es Profesora Titular de Literatura Latinoamericana en la Universidad Sorbonne Nouvelle, especializada en crítica genética y en poesía del Cono Sur. Es autora de Une calligraphie des ombres. Les manuscrits d'Alejandra Pizarnik (Presses Universitaires de Vincennes, 2014) y editora de la correspondencia en francés entre Alejandra Pizarnik y André Pieyre de Mandiargues (Correspondance Paris-Buenos Aires 1961-1972, Ypsilon, 2018). Formó parte del equipo que editó los papeles de trabajo de Juan José Saer y estudió los manuscritos de El paraíso está vacío de Raúl Zurita para la edición Archivos. También ha co-editado, junto con Daniel Balderston, un manuscrito inédito de Borges («La obra de Flaubert», Ensayos, Borges Center, 2019). Además de una introducción a la obra póstuma de César Vallejo, ha publicado artículos sobre Sergio Raimondi, Daniel García Helder, Arnaldo Calveyra, Susana Thénon y Mirtha Dermisache, entre otros.

Edgardo Dobry. Profesor de Literatura Hispanoamericana en la Universitat de Barcelona. Autor de los ensayos Orfeo en el quiosco de diarios. Ensayos sobre poesía (Adriana Hidalgo, 2007), Una profecía del pasado. Lugones y la invención del «linaje de Hércules» (Fondo de Cultura Económica, 2010) e Historia universal de Don Juan: nacimiento y vigencia de un mito moderno (Arpa, 2017). Pertenece al consejo de dirección de Diario de Poesía. Ha traducido, entre otros, a los poetas Sandro Penna y William Carlos Williams, y a los ensayistas Agamben y Calasso. Obtuvo la beca de la Fundación John Simon Guggenheim para la creación literaria. Ha publicado varios libros de poesía; el más reciente, Contratiempo (Adriana Hidalgo, 2013). 
Geneviève Fabry es Catedrática de Literatura Española e Hispanoamericana. Université Catholique de Louvain (UC Louvain) de Bélgica. Es autora de Personaje y lectura en cinco novelas de Manuel Puig (Vervuert/Iberoamericana, 1998) y Las formas del vacío. La escritura del duelo en la poesía de Juan Gelman (Rodopi, 2008). Es coeditora de La literatura argentina de los años 90 (Brill/Rodopi, 2003), Tradición y ruptura en la poesía hispanoamericana del siglo XX (Aleph, 2006), Imaginarios apocalípticos en la literatura hispanoamericana contemporánea (Peter Lang, 2010) y La Biblia en la literatura hispanoamericana (Trotta, 2016). Ha coeditado el monográfico Imaginar el futuro. Resistencia y resiliencia en la literatura y el cine hispanoamericanos contemporáneos (Helix, $\mathrm{N}^{0} 10,2017$ ).

Beatriz Ferrús Antón es Doctora en Literatura Española e Hispanoamericana por la Universitat de València y Profesora Titular de Literatura Hispanoamericana en la Universitat Autónoma de Barcelona. Es autora de Discursos cautivos: convento, vida, escritura (Universidad de Valencia, 2004), Heredar la palabra: cuerpo y escritura de mujeres (Tirant lo Blanch, 2007), Mujer y literatura de viajes en el siglo XIX: Entre España y las Américas (Universidad de Valencia, 2011). Ha coeditado Vida de Sor Francisca Josefa de Castillo (Iberoamericana, 2009) y Mosaico transatlántico: Escritoras, artistas e imaginarios (España-EEUU, 1830-1940) (Universidad de Valencia, 2015). Ha dirigido los proyectos de investigación estatales «Inventario de mitos prehispánicos en la literatura latinoamericana (De los años 80 al presente)» y «Las primeras escritoras y artistas profesionales». Es codirectora de Mitologías hoy. Revista de pensamiento, crítica y estudios literarios latinoamericanos.

María Cecilia Graña es Doctora por Harvard University. Ha sido Profesora Titular de Lengua y literaturas hispanoamericanas en la Universidad de Verona. Entre sus publicaciones destacan La utopía, el teatro, el mito: Buenos Aires en la narrativa argentina del siglo XIX (Bulzoni, 1991), así como las ediciones Il poemetto. Un esempio novecentesco di ricerca poetica (CUEC, 2007), «La suma que es el todo y que no cesa». El poema largo en la modernidad hispanoamericana (Beatriz Viterbo, 2006), y la edición, selección y traducción de la antología Un lungo respiro, de poemas extensos de autoras hispanoamericanas (Edizioni Arcoiris, Salerno, 2018).

Naín Nómez. Doctor por la Universidad de Toronto. Profesor titular y Académico de Excelencia de la Universidad de Santiago de Chile. Ha publicado una docena de libros y más de 60 artículos sobre literatura chilena y latinoamericana. Entre las obras críticas se pueden mencionar los primeros cuatro tomos de la Antología crítica de la poesía chilena (1996, 2000, 2003 y 2006), Un puñado de cenizas. Antología de Nicanor Parra (2015, estudio y selección), además de una serie de trabajos críticos y antologías sobre el poeta chileno Pablo de Rokha. Ha publicado nueve libros de poesía, el más reciente, Historias del reino vigilado (2018) y ha obtenido becas y premios en Canadá y Chile.

María Lucía Puppo es Profesora Titular de Teoría de la Comunicación y Profesora Adjunta de Teoría y Análisis del Discurso Literario en la Pontificia Universidad Católica Argentina. Es Investigadora del Consejo Nacional de Investigaciones Científicas y Técnicas (CONICET). Publicó los libros La música del agua. Poesía y referencia en la obra de Dulce María Loynaz (Biblos, 2006) y Entre el vértigo y la ruina: poesía contemporánea y experiencia urbana (Biblos, 2013). Coeditó el volumen Espacios, imágenes y vectores: desafíos actuales de las literaturas comparadas (Miño y Dávila, 2015). 
Milena Rodríguez Gutiérrez es Doctora en Filología Hispánica y Profesora Titular de Literatura Hispanoamericana en la la Universidad de Granada. Ha publicado Lo que en verso he sentido: la poesía feminista de Alfonsina Storni (Universidad de Granada, 2007) y Entre el cacharro doméstico y la Vía Láctea. Poetas cubanas e hispanoamericanas (Renacimiento, 2012). Es editora de Casa en que nunca he sido extraña. Las poetas hispanoamericanas: identidades, feminismos, poéticas (Peter Lang, 2017), de las antologías El instante raro, de Fina García Marruz (Pre-Textos, 2010) y Otra Cuba secreta. Antología de poetas cubanas del XIX y del XX (Verbum, 2011), y de En la Calzada de Jesús del Monte, de Eliseo Diego (Pre-Textos, 2020). Desde 2014 es Investigadora Principal del Proyecto de Investigación «Las poetas hispanoamericanas: identidades, feminismos, poéticas (Siglos XIX-XXI)», financiado por la Agencia Estatal de Investigación de España. Es autora de varios poemarios, como El otro lado (Renacimiento, 2006).

Márgara Russotto es escritora y académica venezolana de origen italiano. Obtuvo el PhD en Literatura Comparada por la Universidad de São Paulo. Ha sido Catedrática de la Universidad Central de Venezuela donde inició su carrera académica y fundó los Estudios de Género con enfoque multicultural e interdisciplinario y actualmente es Profesora de Literatura Latinoamericana (Brasil/Hispanoamérica/Caribe) en la Universidad de Massachusetts, Amherst. Traductora de autores italianos y brasileños. Ha recibido varios premios tanto en poesía como en ensayo. Entre sus publicaciones pueden destacarse: Bárbaras e ilustradas. Las máscaras del género en la periferia moderna (Tropykos, 1997), Cuatro ensayos sobre Clarice Lispector (2013), así como la edición La ansiedad autorial: formación de la autoría femenina en América Latina: los textos autobiográficos (Universidad Central de Venezuela, 2006) y los poemarios Laboratorio lombrosiano (poesía sobre esculturas, 2012), Tundra (2013), entre otros.

Ina Salazar es Catedrática de Literatura Hispanoamericana en la Universidad de la Sorbonne Paris IV. Es autora de La substancia humana de la poesía. Aproximaciones a la obra poética de César Vallejo (PUF, 2016) y La poesía ante la muerte de Dios. César Vallejo, Jorge Eduardo Eielson, Blanca Varela (Pontificia Universidad Católica del Perú, 2015). Es coeditora de Ecrire sur la poésie (IIndigo, 2008), de Gravitaciones en torno a la obra poética de José Lezama Lima (Éditions Le Manuscrit, 2011) y de La parole imposible: regards croisés autour de la traduction de César Vallejo, Marina Tsvetaeva et Paul Celan (Hermann, 2019). Codirige el Seminario de Investigación interuniversitario Poésies Ibériques et d’Amérique Latine (PIAL). Es autora de varios libros de poesía, como En las aguas de la noche (2014).

Alicia Salomone es Doctora en Literatura Chilena e Hispanoamericana. Profesora Asociada (Profesora Titular) del Centro de Estudios Culturales Latinoamericanos y del Departamento de Literatura de la Universidad de Chile. Entre sus libros figuran: Alfonsina Storni. Mujeres, modernidad y literatura (Corregidor, 2006); así como las ediciones Modernidad en otro tono. Escritura de mujeres latinoamericanas, 1920-1950 (Cuarto Propio, 2004), Caminos y desvíos. Lecturas críticas sobre género y poder en Hispanoamérica (Cuarto Propio, 2010) y Poesía y memoria en el Cono Sur, 1960-2010 (2015). Es coeditora de los libros de crónicas de Alfonsina Storni, Un libro quemado (Excursiones, 2014) y Nosotras. . y la piel. Selección de ensayos de Alfonsina Storni (Alfaguara, 1998). 
